\title{
A revista Veja durante a ditadura civil-militar brasileira: uma discussão a respeito do seu papel no campo do poder e da luta de classes
}

\section{Veja magazine during the civil-military dictatorship in Brazil: a discussion about its role in the field of power and class struggle}

\author{
Edina Rautenberg \\ Mestranda em História (Universidade Estadual do Oeste do Paraná - UNIOESTE) \\ edina_rg@hotmail.com
}

\begin{abstract}
Resumo
O texto procurou abarcar a imprensa, tendo como objeto de estudo a revista semanal Veja durante o período da ditadura civil-militar brasileira, percebendo o posicionamento da revista frente ao poder e à luta de classes. Isto poderá ser percebido através da análise do discurso de Veja sobre os grupos de guerrilhas brasileiros, bem como sobre o posicionamento da revista em relação às multinacionais e às empresas de construção civil. $\mathrm{O}$ artigo sintetiza o desenvolvimento de nossas pesquisas com a revista $V e j a$, entendendo-a como aparelho privado de hegemonia na busca/construção de consenso e também como lugar de articulação de interesses, onde a revista defende seus projetos político-empresariais, mascarados de pretensa neutralidade. Como poderemos perceber, a revista defendeu tanto os empresários, quanto os militares, construindo seu discurso de maneira a elogiar os projetos governamentais e indicar os melhores caminhos para o desenvolvimento econômico, interesse também de Veja.
\end{abstract}

Palavras-chave: Revista Veja. Ditadura civil-militar. Grupos de guerrilhas. Multinacionais. Empresas da construção civil.

\begin{abstract}
The paper has tried to cater to the press, having as its object of study Veja the weekly during the civilmilitary dictatorship in Brazil, noting the placement of the magazine front to power and class struggle. This can be perceived through the discourse analysis of view on the Brazilian guerrilla groups as well as on the positioning of the magazine in relation to multinational companies and construction companies. The article summarizes the development of our research with Veja magazine, understanding it as a private apparatus in the pursuit of hegemony / consensus building and also as place of articulation of interests, where the magazine maintains its political-business projects, masked alleged neutrality. As we see, the magazine defended both the business, as the military, building his speech by praising the way the government projects and indicate the best paths to economic development interests Veja also.
\end{abstract}

Keywords: Veja Magazine. Civil-military dictatorship. Guerrilla groups. Multinational. Companies in the construction industry.

Originais recebidos em: 20/01/11

Aceito da publicação em: 08/03/11

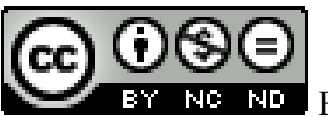

Não-Comercial-Vedada a criação de obras derivadas 3.0 Unported License. 


\title{
Introdução: Veja como partido
}

Partimos do pressuposto metodológico de que a história não é somente um estudo do passado e pode ser, com um menor recuo e métodos particulares, o estudo do presente. A História Imediata $^{1}$ se coloca como um potencial contraponto à visão de história imposta pela mídia, possibilitando tornar compreensível o emaranhado de informações que é despejado diariamente, conferindo racionalidade histórica ao imprevisível, desnaturalizando o naturalizado, ou reinserindo os eventos noticiados em seu processo histórico.

A História Imediata permitiu que os historiadores assumissem o papel de analisar o processo histórico também no presente, função esta cada vez mais ocupada pela Grande Mídia que dita opiniões e exerce influência no campo das decisões políticas e sociais. A hiperabundância de informações veiculadas pela mídia constitui-se em uma história que se resume em: subinformação (quantidade sem qualidade); sucessão de fatos sem nexo; conhecimento fragmentado, não sistematizado e banalizado; os elementos necessários para a compreensão crítica do evento estão sempre ausentes (o evento é apresentado como inevitável; é dissociado de seus antecedentes, retirando-o do processo histórico; é dissociado de seu contexto; é "analisado" em escala local, sem referência a contextos mais amplos; é dissociado de sua relação com o desenvolvimento do capitalismo neoliberal; etc.); entre outros.

Neste sentido, além da importância da História Imediata, estabelecemos nosso objeto na necessidade em discutir o papel da imprensa. Como afirma Carla Silva,

\begin{abstract}
A imprensa também "faz a história" presente. As empresas jornalísticas devem ser vistas como partidos de determinados grupos políticos e econômicos, em consonância com seus programas, ou seja, suas interpretações da realidade acabam interferindo no conhecimento que se tem sobre a realidade e na tomada de posições sobre elas. A sua narrativa nunca é neutra e gera interpretações sobre os diversos aspectos da vida humana: seja o macroeconômico, seja o micro-comportamental. Através delas as pessoas tomam posição e circunscrevem suas visões de mundo. Acaba sendo uma forma de manutenção da hegemonia vigente (Silva, 2006, p. 2).
\end{abstract}

Situando a imprensa como partido através do conceito de Antonio Gramsci, podemos compreender seus interesses econômicos e empresariais, seu projeto político, visão de mundo e atuação ideológica. Para Gramsci os partidos são os canais de organização do consenso. Os principais elaboradores das novas intelectualidades

\footnotetext{
${ }^{1}$ Como referência para autores que discutem a História Imediata, citamos os ensaios presentes na obra de Erico Fernandez (1999) e Agnes Chauveau (1999).
} 
integrais e totalitárias, a pedra de toque de unificação da teoria e prática, entendida como processo histórico real. Segundo Gramsci,

Deve-se sublinhar a importância e o significado que tem os partidos políticos, no mundo moderno, na elaboração e difusão das concepções do mundo, na medida em que elaboram essencialmente a ética e a política adequada a ela, isto é, em que funcionam quase como "experimentadores" históricos de tais concepções. Os partidos selecionam individualmente a massa atuante, e esta seleção operam-se simultaneamente nos campos prático e teórico, com uma relação tão mais estreita entre teoria e prática quanto mais se já a concepção virtualmente e radicalmente inovadora e antagônica aos antigos modos de pensar (Gramsci, 1991, p. 22).

A hegemonia é, para Gramsci, a elaboração de uma nova civiltá, de uma nova civilização. A construção de uma visão de mundo, "diferenciar-se contrapor-se como visão de mundo às demais classes, afirmar-se como projeto para si e para a sociedade; ser direção das classes subalternas e dominadas na construção de uma nova forma civilizatória” (Dias, 1996, p. 10). Neste sentido, o partido atua como porta-voz e organizador. O partido para Gramsci, não é o convencional partido político eleitoral. Trata-se de todo e qualquer aparelho privado de hegemonia que organize um grupo, construindo o que ele chama de vontade coletiva organizada. A hegemonia deve ser entendida, portanto, como um elemento mais amplo, sendo o consenso, formas específicas dessa hegemonia. O consenso se torna o elemento por meio do qual a hegemonia passa a fazer sentido para as pessoas.

A imprensa é, portanto, entendida a partir de Gramsci, como um órgão políticopartidário, capaz de estipular "visões de mundo", de maneira a contribuir com as classes dominantes na construção de hegemonia, necessária para a consolidação de seus projetos capitalistas. Segundo Antonio Gramsci, o capitalismo mantém o controle não apenas pela repressão, mas também através da coerção ideológica, por meio de uma cultura hegemônica na qual os valores da burguesia se tornam o "senso comum". Gramsci adverte, porém, que a hegemonia não é aceita de forma passiva, está sujeita à luta, à confrontação. Por isso quem a exerce, tem de renová-la continuamente, reelaborar, defender e modificar, procurando neutralizar o adversário, incorporando as suas reivindicações, mas de maneira invertida. A imprensa, entendida como um "aparelho privado de hegemonia" seria uma das formas pelas quais as classes dominantes conseguem executar seus projetos, mas é também campo da luta de classes. A imprensa torna-se, portanto, importante instrumento de alguns atores dessa luta, onde os setores dominantes implementam seu programa partidário, apresentado e recoberto de suposta neutralidade, realizando uma distribuição específica de poder, de hierarquia e 
de influência, e fazendo com que as classes dominadas tomem para si um projeto construído e destinado para atender os interesses do capital.

Neste sentido, devemos afirmar o compromisso social de nossas pesquisas enquanto contraponto ao Pensamento Único ${ }^{2}$, questionando o monopólio exercido pela mídia e revogando para os historiadores o papel de interpretar os processos sociais (papel este cada vez mais comandado pela Grande Mídia, que advoga a função de "escrever a história", tornando-a mercadoria). Como afirma Josep Fontana, "nem os métodos nem a teoria são objetivo final do nosso trabalho, são apenas ferramentas para tratar de entender melhor o mundo em que vivemos e ajudar os outros a entendêlo, a fim de contribuir para melhorá-lo, o que faz falta" (Fontana, 1998, p. 37). Nossas pesquisas devem partir da premissa de Marx, de serem capaz de transformar o mundo e não só interpretá-lo. Neste sentido, demonstrar o papel da imprensa enquanto construtora de hegemonia permite colocarmo-nos críticos ao sistema capitalista excludente, demonstrando cada vez mais a necessidade de problematizarmos as notícias veiculadas pela mídia que tentam tornar-se história. Neste sentido, apontamos nossas pesquisas a respeito da revista semanal Veja durante a ditadura civil-militar brasileira.

René Armand Dreifuss afirma que o golpe não foi simplesmente o resultado de uma ação militar e sim de atividades específicas de interesses empresariais, públicas e encobertas, tanto táticas quanto estratégicas, que eram desenvolvidas pela elite orgânica, objetivando conter as forças populares, desagregar o bloco histórico-populista e levar os interesses multinacionais e associados ao governo político através de um golpe de Estado civil-militar. Segundo Dreifuss, a conquista do poder político pela elite orgânica não foi simplesmente um resultado da crise político-econômica do período e o imediato colapso do regime. Nessas críticas condições, a elite orgânica tentou levar adiante uma campanha para dominar o sistema tanto em termos políticos quanto ideológicos. Segundo Dreifuss, a quebra da convergência de classe vigente e a ruptura da forma populista de dominação foram alcançadas pelo bloco de poder multinacional e associado através do exercício de sua influência em todos os níveis políticos. Como demonstra Dreifuss, o período de ação de classe organizada, estendeu-se de 1962 a 1964. Politicamente, significou uma mobilização conjuntural para o golpe, quando a

\footnotetext{
${ }^{2}$ Manifestado claramente a partir dos meios de comunicação que, através de uma falsa liberdade de expressão, mascaram o controle e a criação, concentrada e centralizada, das informações. Dentre os seus principais objetivos, podemos destacar dois: a reprodução do sistema dominante (fundamentado na superexploração e na exclusão social) e, conseqüentemente, a impossibilidade de se gestar qualquer alternativa a este sistema.
} 
estratégia se converteu em política e atividades político-partidárias finalmente se transformaram em ação militar ${ }^{3}$.

As reflexões aqui apresentadas constituem um encadeamento de temas de pesquisa que foram surgindo a partir das investigações. Estas serão divididas em tópicos que situaremos a seguir.

\section{A luta armada vista pela Veja}

Primeiramente nos referimos às pesquisas relacionadas aos grupos de guerrilhas durante a ditadura militar ${ }^{4}$. Os trabalhos tomaram o recorte temporal de 1968 (ano de lançamento de Veja) a 1972 em primeiro momento, e de 1973 a 1980 em segundo momento. O primeiro recorte procurou considerar as guerrilhas no auge de suas ações armadas nas cidades, até o período considerado como de término de suas ações, tomando como referência as bibliografias que tratavam sobre o assunto ${ }^{5}$. A análise procurou abarcar o posicionamento da revista em relação aos grupos de guerrilhas, caracterizando o discurso de Veja em relação aos grupos, suas idéias, ações armadas, a ação policial, a repressão, o combate às guerrilhas, as quedas dos grupos e o seu fim.

O que podemos perceber com a análise é que a revista procurou construir uma imagem negativa dos guerrilheiros, associando-os ao banditismo e a subversão. Uma maneira utilizada por Veja de caracterizar os guerrilheiros esteve na maneira em que o semanário é organizado: o título dado pela revista às seções em que foram abordados temas relativos aos guerrilheiros é "Terror" ou "Subversão". Quando a revista não apresentou os fatos nestas seções, trouxe títulos com especificações ou alusões ao terrorismo. Podemos perceber que Veja adotava uma posição de repulsa aos guerrilheiros, caracterizando-os como bandidos e terroristas e especialmente, desnecessários para a obtenção do processo de redemocratização, almejado pela revista.

Veja apresentou os atentados, caracterizando-os como fruto de especialistas, onde os guerrilheiros agiriam com "sangue frio, precisão, imaginação, habilidade" 6. Veja foi atuando de maneira a criar um ambiente de medo e pavor entre seus leitores,

\footnotetext{
${ }^{3}$ Dreifuss (2006), p. 246.

${ }^{4}$ Análises obtidas através de projetos de iniciação científica, PIBIC/UNIOESTE/PRPPG (2005-2006) e PIBIC/UNIOESTE/CNPq (2006-2007).

${ }^{5}$ Entre elas citamos: Gorender (1987), Reis Filho (1990), Mir (1994), Ridenti (1993).

${ }^{6}$ Veja. Mais assaltos. Roubaram 80 milhões e ficou uma pergunta: são terroristas? A técnica do assalto e as armas lembram outros grandes roubos ocorridos em São Paulo. Ed.06 - 16/10/1968 p. 25.
} 
pois não apresentou os objetivos das ações guerrilheiras, que através de diferentes modos e ideologias pretendiam acabar com a ditadura e instaurar o socialismo ou o comunismo no Brasil. De diferentes maneiras, Veja foi apresentando os guerrilheiros como indivíduos perigosos, que assassinavam pessoas comuns: "E a figura do terrorista já faz parte da paisagem urbana: mais de um homem, mais de uma vez, já parou o trânsito de ruas próximas ao centro com rajadas de metralhadoras de um respeitável arsenal" ?.

A análise constatou também a prática de Veja em suscitar a necessidade de combate às guerrilhas e em autenticar a repressão, insinuando que as ações armadas praticadas pelos guerrilheiros poderiam estar visando causas particulares e não projetos de contestação. Através da estratégia de culpar os próprios guerrilheiros pelo aumento da repressão, Veja utilizou-se de argumentos que justificavam as ações violentas dos militares contra os grupos de guerrilhas. Segundo a revista, "para enfrentar $o$ terrorismo, e preciso ser um terrorista" ${ }^{8}$. E dessa maneira Veja relacionou a prática policial de violência e destruição aos ideais dos guerrilheiros, colocando a população a associar as práticas depredatórias dos militares às práticas revolucionárias dos guerrilheiros.

O fim das guerrilhas foi um assunto pedagogicamente retratado por Veja. Mesmo no período em que as ações armadas atingiam seu ápice, a revista apresentou frases de oficiais anunciando um fim próximo. "Um combate que se aproxima do fim, segundo os oficiais integrantes dos órgãos federais de segurança" 9. O constante anúncio de aniquilação dos movimentos de guerrilhas poderia deixar os demais grupos temerosos e apreensivos em continuar a luta armada, já que a continuidade da luta levaria, como afirmava a revista, à autodestruição.

Veja procurou criar consenso, desde as primeiras matérias realizadas sobre os grupos guerrilheiros, de que estes jamais obteriam sucesso, que já estavam praticamente acabados. O fim das guerrilhas foi apontado freqüentemente, sendo que Veja procurou constantemente trazer citações de oficiais envolvidos na "caça" aos guerrilheiros, para que estes "relatassem" o cerco que se fechava cada vez mais em torno dos grupos de luta armada. Além disso, a revista apresentou apenas dados que confirmavam esse propósito, deixando de mencionar sobre eventuais ações que poderiam estar sendo

\footnotetext{
${ }^{7}$ Veja. Ele assalta em nome do terror. Ed. 37 -21/05/1969. p. 18.

${ }^{8}$ Idem.

${ }^{9}$ Veja. O terror de rosto descoberto. Ed.48 - 06/08/1969. p.16-18. 
praticadas pelos guerrilheiros. Percebe-se, portanto, a posição de Veja de defesa do sistema instaurado com o golpe de 1964, sendo que para a revista, a redemocratização só seria obtida através dos militares, cabendo a eles a decisão do melhor momento para isto. Os grupos de guerrilhas seriam desnecessários, pois a mudança só ocorreria dentro da ordem ${ }^{10}$.

O segundo recorte de pesquisa é decorrência do primeiro e procurou caracterizar o discurso de Veja após o auge das ações guerrilheiras, verificando como a revista garantiu a extinção dos grupos e abafou as pequenas ações que ainda ocorriam. A pesquisa surgiu do contato com a revista e a indagação dos motivos de Veja continuar noticiando os guerrilheiros mesmo após ter decretado o seu fim em 1972. Além disso, de 1972 a 1974 ocorreu o movimento de guerrilha rural considerado o mais importante do Brasil, chamado Guerrilha do Araguaia ${ }^{11}$. Na pesquisa procuramos evidenciar se Veja apresentou indícios deste movimento e como a revista o caracterizou quando as notícias sobre o mesmo foram liberadas pela censura ${ }^{12}$, por volta de 1976 . O trabalho analisou ainda como a revista foi reconstruindo seu próprio discurso, procurando modificar sua própria posição em relação às guerrilhas e reconstruindo a memória sobre ela e sobre os guerrilheiros no período.

O que mais nos chamou atenção na pesquisa foi perceber como a revista adequou o seu discurso de acordo com os acontecimentos do governo ditatorial. Inicialmente, em 1974, com a distensão aplicada por Geisel como forma de aliviar a

\footnotetext{
${ }^{10}$ Para mais resultados da pesquisa ver: Rautenberg (2010).

${ }^{11}$ Para discussões a respeito da Guerrilha do Araguaia citamos: Golin (1996) e Morais e Silva (2005).

${ }^{12}$ Segundo Tais Morais e Eumano Silva (2005), em 1973 ocorre uma infiltração de militares e civis em toda a área do Araguaia, no Pará. Chamada "Operação Sucuri", essa infiltração teria a intenção de recolher informações sobre os guerrilheiros que estavam atuando naquela região para assim, montar uma estratégia de aniquilação total do grupo do PCdoB. A preocupação em manter o sigilo sobre a operação era importante para a eficácia desta. A existência de focos guerrilheiros poderia incentivar a reorganização de outros grupos. Nesse sentido, a imprensa estava proibida de abordar qualquer notícia envolvendo a guerrilha do $\mathrm{PCdoB}$, bem como de outros grupos guerrilheiros. A censura pairou em Veja até 1976 e, além disso, a revista não tinha interesse em divulgar notícias que pudessem comprometer o processo de abertura democrática que ela defendia. Segundo Morais e Silva, o período de outubro de 1973 a dezembro de 1976 é caracterizado pelo extermínio da guerrilha do Araguaia. A "Operação Marajoara" - planejada pela $8^{\mathrm{a}} \mathrm{RM}$ com colaboração da CIE - começou em outubro de 1973 e visava, em um primeiro momento, prender e neutralizar a rede de apoio aos guerrilheiros e, em um segundo, vasculhar as áreas de depósito e esconderijo. A operação contou com mais ou menos 300 militares, sendo que o relatório do CIE apresentava a existência de apenas 63 guerrilheiros nesse período. Segundo os autores, "o comando guerrilheiro reagiu como pôde. Cansados, doentes e com armas insuficientes, enfrentaram as forças do governo agora preparadas para o combate na selva" (Morais; Silva, 2005: p. 468). Além disso, o governo investia em projetos que visassem uma adesão por parte da população ao governo como as ACISO (Ações Cívico-Sociais), as obras faraônicas (como a Transamazônica), entre outras, que auxiliavam na neutralização do trabalho de aproximação dos guerrilheiros com os moradores, além de ajudarem a disfarçar a perseguição aos guerrilheiros.
} 
crise institucional do regime, Veja apóia a "luta coletiva" considerada necessária para a viabilidade da distensão. Nesta "luta coletiva", a extinção dos grupos de guerrilhas foi considerada fundamental. Construindo consensos sobre o os erros dos guerrilheiros e o fim das guerrilhas, Veja acalmaria o animo de alguns descontentes - como estudantes, operários, etc. -, ou pelo menos, tentaria evitar que estes pudessem vir a construir uma base forte com os movimentos guerrilheiros.

Foi possível também visualizar em Veja reflexos dos embates dentro do próprio governo Geisel e, especialmente, o apoio da revista aos militares castelistas, contra os militares "linha dura" ${ }^{13}$ que se alteravam no poder e eram considerados contrários ao processo de distensão pretendido também pela revista. Kucinski (1982) discute esse processo de abertura democrática como resultado de crises que vinham assolando a ditadura e que teriam vindo a se intensificar com a crise do "milagre econômico". Diante de uma burguesia que se adiantava no processo de ruptura com o regime autoritário, bloqueando a estatização como solução natural para abrir assim caminhos ao neoliberalismo, o estado-maior militar optou por um processo de abertura controlado. Através de sístoles e diástoles (para utilizar o vocabulário do próprio Golbery), Geisel afastaria o governo autoritário, lenta e gradualmente, com avanços e retrocessos, e resolveria o problema imediato da facção dominante de vencer as resistências internas ao projeto de abertura, oriundas do aparelho de repressão e da "linha dura". Tendo em vista estas questões, procuramos caracterizar o discurso de Veja sobre os guerrilheiros dentro desse contexto de crise interna da ditadura militar, percebendo o posicionamento da revista sobre as guerrilhas nesses momentos de "contrações" e "distensões" realizadas pelo general Geisel.

Pode-se perceber que a revista procurou reconstruir os acontecimentos envolvendo os guerrilheiros no período auge de suas ações (1968-1970), questionando a tortura e à repressão exacerbada. Entretanto, a repulsa à opção da luta armada permanece forte na revista, que crítica o silêncio da ditadura em relação às mortes, mas reafirma as opções "erradas" dos guerrilheiros. O exemplo mais claro disto são os

\footnotetext{
${ }^{13}$ Durante muito tempo adotou-se essa idéia simples de "moderados" e "linha dura" para explicar as idas e vindas do regime. Entretanto, por mais que o esquema tenha sido útil para explicar as oscilações e disputas internas dos militares, pesquisadores estão revendo esta questão. Um exemplo é o trabalho de Carlos Fico (2004) que, em uma análise mais apurada dos governos do período, revelou que as divergências na caserna eram muito mais sutis. Um exemplo é o governo Castelo Branco, cuja imagem cristalizada foi de uma figura moderada, legalista. Entretanto, seu governo não foi marcado apenas pela moderação. Ele fechou o Congresso, proibiu atividades políticas dos estudantes, decretou o AI-2 e foi conivente com a tortura. Mesmo que Castelo tenha compartilhado da visão de que os militares deveriam ter uma atuação mais moderada, não foi isso que aconteceu na prática.
} 
acontecimentos envolvendo a morte do principal líder, Carlos Marighella ${ }^{14}$. Em 12/11/1969, Veja havia dedicado uma matéria de capa para falar da morte de Marighella. Com o título "O terrorismo morreu com Marighella?", a revista dedicou 12 páginas para relatar os episódios e interpretações sobre a morte do líder guerrilheiro. Quando a revista retratou a participação de Marighella no enfrentamento policial que resultou em sua morte, Veja procurou caracterizá-lo como vítima, já que o guerrilheiro "nem chegou a pegar sua arma" 15 , durante o tiroteio. Veja pareceu se portar contra o exagero da repressão ao guerrilheiro, entretanto, a ênfase da matéria é uma visão negativa sobre Marighella. A revista cita trechos do "Mini-Manual do Guerrilheiro Urbano" escrito por Marighella, apontando que o próprio líder não teria seguido as “instruções" do seu Manuel. Ou seja, Veja procura através do sarcasmo e de outras maneiras, desconstruir as qualidades do guerrilheiro em detrimento das opções escolhidas por Marighella para conduzir suas ações.

Apesar de haver indícios sobre a repressão, percebemos que esta foi amenizada pela revista, dando atenção a outros elementos para encobrir o tiroteio. A denúncia passa a se configurar em Veja somente a partir de 1979 (dez anos depois!), quando em matéria sobre a morte do delegado Sérgio Paranhos Fleury, Veja reconstrói o episódio da morte de Marighella.

Na matéria de 09/05/1979, Veja noticiou a morte do delegado Sérgio Paranhos Fleury. A revista construiu seus discursos procurando provocar certo drama sobre o acontecimento, sendo que a matéria chega a se assemelhar a uma novela na qual não se tem um final feliz: Fleury passeava com seu barco, bêbado, no litoral de Ilhabela, quando de sua morte.

É interessante notar que, nessa "novela", Veja procura caracterizar seu ator principal (Fleury) com elementos discursivos que levam o leitor a uma imagem negativa do general. Entre estes podemos destacar as expressões "alvo de ódios intensos", "famigerado comissário", "jamais dormia”, "violência de Fleury”, "fria determinação", "empregar violência com quem quer que estivesse de posse de informações valiosas", etc. A revista procura destacar também o fato de Fleury estar bêbado e que isto teria contribuído para sua morte. Além disso, a todo o momento há a associação de Fleury à tortura, sendo que Veja chega a trazer a fala de um ex-preso

\footnotetext{
${ }^{14}$ Para mais detalhes sobre a morte de Marighella ver: Betto (2006) e José (2004).

${ }^{15}$ Veja. Estratégia para matar o terror. Ed. 62 - 12/11/1969. p. 22.
} 
político capturado pelo delegado civil, afirmando que Fleury "torturava como se fosse uma coisa corriqueira, como se estivesse comendo batatas" 16.

É nesse sentido de denúncia das torturas que Veja trata das investigações que levaram Fleury "à sua vitima mais famosa - o ex-deputado comunista Carlos Marighella, chefe da organização terrorista Aliança Libertadora Nacional (ALN)" 17. Segundo a revista, logo após ter assumido seu posto no DEOPS, Fleury começou a perseguir frades dominicanos e, "convencido de que havia informações a arrancar do grupo de religiosos, o delegado achou que chegara o momento de recorrer à tortura" 18. Nesse sentido, Veja vai reconstruir o acontecimento que envolveu a morte de Marighella: "Na semana passada, policiais que participaram do cerco a Marighella sustentaram que, ao contrário da lenda, não houve troca de tiros naquela noite" 19. Encontramos aí uma forma de a revista reforçar a sua posição de 1969, quando Veja caracterizou Marighella como vítima do cerco policial. Entretanto, a revista não problematiza os motivos para o encobrimento do acontecimento que revelariam o verdadeiro episódio da morte de Marighella. Se em 1969 a revista estava sob censura, impedida de noticiar à verdadeira versão sobre o acontecimento, em 1979 Veja já se encontrava no terceiro ano sem censura ${ }^{20}$, o que comprova que se a revista não questionou o governo ditatorial foi por posicionar-se em favor do mesmo. Veja parece reproduzir a "defesa oficial" ao afirmar que "segundo os policiais, foi somente para encobrir as reais razões da morte de Stella que se teria montado à versão do tiroteio" ${ }^{21}$, remetendo também à idéia de repulsa a opção de Marighella em militar pela luta armada.

Enfim, procuramos demonstrar que mesmo após a contestação da manipulação dos fatos envolvendo a morte de Marighella, a intenção de Veja não era de defesa aos guerrilheiros e sim, de adequar-se aos acontecimentos do governo ditatorial. A revista contestou o fato e não a morte de Marighella. Veja, bem como toda a imprensa

\footnotetext{
${ }^{16}$ Veja. Um símbolo da década. O homem que encarnou a violência dos anos 70 morre no litoral de Ilhabela - e com isso se encerra inesperadamente a explosiva "questão Fleury". Ed. 557 - 09/05/1979. p. 32 .

${ }^{17}$ Idem. p. 31.

${ }^{18}$ Idem.

${ }^{19}$ Idem.

${ }^{20}$ A censura em Veja teve várias fases, passando de bilhetinhos e telefonemas, envio de material à policia antes da publicação, à um censor na redação que lia todas as matérias. A censura é suspensa na Veja em 1976, num episódio envolvendo a demissão de Mino Carta e um empréstimo governamental foi concedido à Editora Abril.

${ }^{21}$ Veja. Um símbolo da década. Op. Cit. p. 32. Stella Borges Morato era investigadora, e participava do cerco à Marighella. Fleury teria atirado acidentalmente em Stella ao confundi-la com algum integrante da escolta de Marighella. A investigadora morreu no local.
} 
hegemônica, tratou de construir seu discurso de maneira a estabelecer parâmetros que não buscassem um questionamento mais radical da ditadura militar. Os grandes empresários de comunicação estavam insatisfeitos com os rumos do regime militar. Entretanto, eram complacentes, visto o extraordinário crescimento patrimonial advindo de empréstimos e investimentos governamentais. Veja cresceu e se consolidou durante o período da ditadura militar.

No período de análise, podemos perceber que Veja refletiu a crise existente no governo Geisel e acabou tomando para si o projeto de desmoralizar o setor mais radical do governo, já que só após a contenção da "linha dura" é que Geisel desativaria a estrutura autoritária. Além disso, a demissão de Sylvio Frota em 1977 e morte de Fleury em 1979 representavam contextos perfeitos para a revista investir na questão dos direitos humanos e da redemocratização. Neste sentido, ficam claras as intenções de Veja quando, reportando-se a Fleury, afirma que "não foi ele o grande cérebro da repressão, nem seu articulador político - mas raramente em qualquer regime de força dos tempos contemporâneos, alguém personificou tão avassaladora, como ele, o aparelho repressor" 22.

As guerrilhas eram uma forma de contestação social que se propugnava acabar com o pacto burocrático-autoritário (que reuniu setores da burguesia, a burocracia militar e civil) consolidado com o Golpe de 64. Veja declarava-se um órgão de contestação à ditadura militar, que lutou e apoiou a democratização. Porém, com as análises realizadas verificou-se que seus interesses estavam em consonância com os projetos dos governos militares. Portanto, Veja contribuiu com a ditadura militar moldando, formando preferências e construindo adaptações às "regras do jogo capitalista", porque via através desta uma maneira de ver consolidada sua política partidária e concretizada suas estratégias de $\operatorname{poder}^{23}$. Desta maneira, a revista formulou um ajustamento político e social para toda a sociedade e, como pretendemos demonstrar empiricamente, também aos grupos de guerrilhas que eram considerados desnecessários e prejudiciais para a obtenção dos objetivos capitalistas de Veja.

\footnotetext{
22 Idem. p. 33.

${ }^{23}$ Para mais resultados da análise ver: Rautenberg (2007). 


\section{O otimismo da ditadura nas páginas da revista}

Tendo abordado o posicionamento discursivo de Veja e seu papel na luta de classes, passamos a analisar o posicionamento político partidário da revista frente aos projetos econômicos implementados pela ditadura militar brasileira ${ }^{24}$. Como sabemos, o regime ditatorial não se manteve apenas devido à coerção física, mas soube utilizar perfeitamente, armas de coerção ideológica.

O "milagre econômico" foi um projeto econômico que vinha sendo gestado anteriormente ao Golpe Militar de 64, mas que teve sua "evolução" durante o governo de Castelo Branco, Costa e Silva, até o boom, entre 1968 e 1973 (governo Médici). Como demonstram Sonia Mendonça e Virginia Fontes, o objetivo da política econômica ditatorial, passou a ser a criação de novas alternativas de financiamento, tanto interna como externamente. Do ponto de vista do financiamento interno da acumulação, a "fórmula mágica" adotada foi o arrocho salarial. "Afinal, as formas clássicas de superação das crises capitalistas são a intensificação da exploração do trabalho e a própria concentração das empresas e do capital" (Fontes; Mendonça, 2004:22). O Estado passou a desempenhar a função do grande capital, aceitando e estimulando associações, especialmente com o capital estrangeiro. Segundo Fontes e Mendonça,

Estava formado o tripé sobre o qual apoiar-se-ia a economia brasileira. $\mathrm{O}$ processo de acumulação ancorava-se num setor de bens de capital predominantemente vinculado ao Estado; no de bens duráveis multinacional, impulsionador do processo, e, finalmente, num setor de produção de bens de consumo baseado no capital nacional (Fontes; Mendonça, 2004:31).

Partindo destas discussões a respeito do papel das multinacionais no desenvolvimento da economia brasileira ${ }^{25}$, passamos a analisar o discurso da revista $V e j a$ em relação às multinacionais, verificando assim, o posicionamento da revista, entre os anos de 1968 a 1975. Além disso, procuramos com a pesquisa, analisar como a revista representou o tripé existente entre o capital externo, o governo e o capital nacional, verificando qual o papel de Veja na construção ideológica de permanência desse tripé.

$\mathrm{O}$ que podemos perceber durante nossa pesquisa foi que inicialmente Veja caracterizou-se por discurso altamente elogioso e exaltador às multinacionais,

\footnotetext{
${ }^{24} \mathrm{O}$ que engloba nosso terceiro projeto e também o Trabalho de Conclusão de Curso em História, pela UNIOESTE, defendido em 2008.

${ }^{25}$ Além das discussões citadas acima, foram de suma importância para a pesquisa, os trabalhos de Evans (1980), Mendonça (1985), Padrós (1996) e Viana (2005), citados na bibliografia.
} 
colocando-as como indispensáveis e altamente benéficas para a economia brasileira. Com o passar do tempo e o início da crise do "milagre econômico" este discurso passou a se transformar, momento este em que Veja indaga a participação das multinacionais, especialmente devido a sua concorrência dentro do mercado interno que estaria afetando algumas empresas nacionais de peso. Desta maneira, procuramos caracterizar o discurso de Veja, demonstrando como ela foi adaptando suas matérias de maneira a defender seus interesses, porém demonstrando-os como interesses da nação. Além disso, mesmo quando das críticas, a revista continuou afirmando a importância das multinacionais, caracterizando-as como um mal necessário, já que só elas garantiriam a manutenção do padrão capitalista de acumulação.

Um dos momentos em que Veja indaga a participação das multinacionais no Brasil nos chamou atenção devido ao setor em questão que estaria sendo prejudicado: as empresas de construção civil. Vejamos a matéria:

Em 28/2/1973, Veja tratou da instalação da fábrica de automóveis da Fiat em Belo Horizonte. Após relatar as negociações entre os governos de diferentes estados brasileiros para que a fábrica multinacional se instalasse em seu estado, garantindo um maior desenvolvimento industrial do mesmo, Veja apresenta uma característica interessante que pode ser percebida nestas negociações:

\begin{abstract}
Os entendimentos iam tão bem que algumas fontes governamentais, otimistas, anunciavam sempre para o dia seguinte a assinatura do acordo ítalo-mineiro. Mas, de tanto esperar, Belo Horizonte começou a fabricar boatos, que o deputado Dalton Canabrava, do MDB, transformou em perigosa denúncia: "Como Salomé, que exigiu a cabeça de São João, a Fiat já conseguiu que fossem colocados na bandeja a Demisa e a Construtora Mendes Júnior".

Concorrência - Além de insinuar que teria havido manobras pouco claras na antiga venda da Demisa ao grupo italiano, Canabrava dava gongórica ênfase ao fato de estar em fase final de apuração o resultado da concorrência para a construção da Usina Hidrelétrica de São Simão, no Rio Grande. Nesta disputa, a construtora mineira Mendes Júnior e o consórcio formado pela Construtora C.R. Almeida (com sede no Rio) e a Empresit Girola Lodigiani, do grupo Fiat, estão praticamente empatados. O deputado acha que a Fiat só instalaria a sua fábrica em Minas se ganhasse a concorrência da usina - obra de 700 milhões de cruzeiros. Franco Urani reagiu prontamente, dizendo que a "Fiat não leiloa decisões" ${ }^{26}$.
\end{abstract}

Percebe-se que a questão da concorrência das multinacionais com as empresas nacionais começa a ganhar destaque nas páginas de Veja. Outro ponto que merece atenção é o fato de a "chantagem" da Fiat ser evidenciada quando as empresas prejudicadas são as referentes à construção civil, em especial, a "gigante da

\footnotetext{
${ }^{26}$ Veja, 28/2/1973. p. 60
}

Em Debat: Rev. Dig., ISSNe 1980-3532, Florianópolis, n. 5, p. 64-85, 2011 
construção", Mendes Júnior. Cabe-nos perceber a revista Veja enquanto lugar de articulação de interesses e seu papel enquanto defensora de projetos políticoempresariais de alguns setores. Parece-nos aqui que, apesar de todo o discurso "entusiasmado" dos benefícios da instalação das multinacionais no Brasil, Veja está nitidamente defendendo os interesses do setor nacional da construção civil, a qual possivelmente a revista teria identificação.

Porém a revista procura apenas relatar esta concorrência, não apresentando, inicialmente, nenhum posicionamento claro. Segundo Veja,

Definidos os principais pontos do acordo, a última atividade dos emissários da Fiat foi viajar sexta-feira passada ao Rio, acompanhados do secretário da Fazenda de Minas, Fernando Roquete Reis, encarregado de ajudar a abrir algumas portas ministeriais. Tarefa praticamente desnecessária, pois no primeiro semestre de 1972 Rondon Pacheco já afirmava que o governo federal daria "a melhor acolhida" ao projeto italiano ${ }^{27}$.

Veja constrói seu discurso de maneira a tentar encobrir seu posicionamento. Dentro de uma série de descrições que a revista traz sobre as negociações, Veja procura criar uma ilusão de neutralidade, como se a mesma estivesse narrando os fatos. Porém, alguns elementos do discurso como o fato de afirmar que a tarefa era praticamente desnecessária porque o governo já havia dado seu veredicto, demonstram a tentativa de Veja em problematizar a questão defendendo seus interesses ${ }^{28}$.

Tendo em vista estes elementos, somados aos já encontrados durante o trabalho com as guerrilhas em $V e j a^{29}$, e a quantidade de matérias na revista sobre os "grandes projetos militares", julgamos ser necessário trabalhar com as "grandes obras" do governo ditatorial. Neste sentido, utilizamos o recorte de três obras: a Rodovia Transamazônica, a Ponte Rio-Niterói e a Hidrelétrica de Itaipu. O recorte se justificou por serem parte das "maiores" construções daquele período e, em especial, pela predominância de matérias sobre elas em Veja. Porém, um dos elementos que nos chamou muito a atenção durante o levantamento de fontes, foi a forte presença das empreiteiras da construção civil nas páginas da revista. Nosso objetivo com o trabalho era perceber o discurso da revista em relação às chamadas "grandes obras" do governo

\footnotetext{
${ }^{27}$ Veja, 28/2/1973. p. 61

${ }^{28}$ Para uma análise mais detalhada acerca do posicionamento de Veja sobre as multinacionais no Brasil ver: Rautenberg (2008).

${ }^{29}$ Durante o levantamento e sistematização das fontes percebemos que nos anos de 1974 e 1975 não havia matéria de Veja sobre os grupos guerrilheiros. Assuntos de destaque na revista durante esses dois anos foram as obras e ações realizadas pelo governo militar no Brasil. Entre essas obras estão as usinas hidroelétricas, a ponte Rio-Niterói, a Transamazônica, além de ações “educativas” e de auxílio a regiões "desabitadas" e "pouco auxiliadas" da região amazônica.
} 
militar, entretanto, a ênfase da revista em praticamente todas as matérias fichadas, era voltada para a figura dos empreiteiros.

Uma das características marcantes do desenvolvimento do capitalismo no Brasil diz respeito ao papel do Estado como fator de impulso à industrialização. Como demonstrou José Serra (1982), esse papel foi exercido não apenas através de suas funções fiscais e monetárias e de controle do mercado de trabalho ou de sua função de provedor dos chamados bens públicos, mas, sobretudo pela definição, articulação e sustentação financeira dos grandes blocos de investimento que determinaram as principais modificações estruturais da economia no pós-guerra; e pela criação da infraestrutura e produção direta de insumos intermediários indispensáveis à industrialização pesada. Neste sentido, adotaram-se políticas destinadas a incrementar as funções produtivas do aparato estatal através das intervenções fundamentais: a promoção de certos ramos da indústria considerados estratégicos para o funcionamento do modelo de acumulação e o impulso às obras públicas para ampliar e melhorar o raio de ação do capital. A época do chamado "milagre econômico" foi marcada pela proliferação dos grandes projetos de infra-estrutura, reforçando o slogan político de "Brasil Potência" 30.

Diversos estudos econômicos sobre a Indústria da Construção destacam o papel influente da construção como vetor impulsionador do crescimento econômico, devido o tamanho do seu produto como proporção do valor adicionado total das atividades, seu elevado efeito multiplicador de renda e emprego e sua interdependência estrutural ${ }^{31}$. Além disso, historicamente, o poder público é o principal cliente do setor da construção civil $^{32}$. O período da ditadura militar correspondeu ao auge da ação das empreiteiras. Segundo dados levantados por Marques (1998), entre 1960 e 1978 foram construídas 84 barragens, sendo 13 delas com mais de $1000 \mathrm{MW}$ de potência (inclusive Itaipu, a maior do mundo com 8.400 MW). Desse total, 56 delas foram construídas por apenas 7 empreiteiras. A concentração aumenta se observarmos a lista das maiores obras: as 13 maiores usinas foram construídas por apenas 6 empresas: Camargo Corrêa, Mendes Júnior, Andrade Gutierrez, C.R. Almeida, Servix e Cetenco.

\footnotetext{
${ }^{30}$ Para maiores discussões sobre a ideologia ufanista propagada pela ditadura militar ver: Fico (1997).

${ }^{31}$ Entre os estudos citamos: Chaves (1985); Alves (1997); Teixeira (2009); etc.

${ }^{32}$ Segundo artigo elaborado pela Câmara Brasileira da Indústria da Construção Civil (CBIC), o setor construtor esteve sempre na subordinação direta da performance econômica do país e das ações do poder público. A construção, sendo particularmente sensível ao nível de renda e ao volume de créditos disponíveis, cresce em grande parte por efeito da expansão do produto nacional, enquanto é, ao mesmo tempo, fator de aceleração do crescimento econômico, dado seu enorme efeito multiplicador sobre o processo produtivo e sobre os investimentos. (CÂMARA BRASILEIRA DA INDÚSTRIA DA CONSTRUÇÃO CIVIL (CBIC), 1998, p. 4)
} 
Neste sentido, interessou-nos problematizar os motivos de Veja ter dado tanto destaque a este setor específico do capital nacional. Analisando o discurso da revista sobre as "grandes obras", percebemos também a posição de Veja sobre as construtoras destas obras, demonstrando assim a defesa da revista a algumas empresas específicas desse setor que, "coincidentemente", estavam entre as de maior capital ${ }^{33}$.

A pesquisa demonstrou que Veja utilizou-se de especificidades próprias para tratar de cada uma das três obras. Neste sentido, apontamos as conclusões que chegamos com a análise das matérias.

Em relação à Transamazônica, Veja embarcou na ideologia de "Brasil Grande", divulgando a integração nacional, a segurança nacional e o desenvolvimento nacional que esta obra de grande porte representaria para o Brasil. A lógica do progresso parece estar clara na perspectiva dos "trabalhadores" selecionados e apresentados pela revista e na justificativa de Veja. Mesmo enfrentando uma jornada de 18 horas de trabalho e apenas 6 horas de sono (que eram divididas com a luta contra os pernilongos), a idéia de levar o progresso à Amazônia permanece presente no superar das dificuldades. Quando começam a surgir questionamentos contrários à construção da rodovia, Veja abre espaço para a crítica, mas a resposta de Delfim Neto ganhou o triplo de espaço na revista, concluindo que a construção da Transamazônica, ocupando economicamente a Amazônia e criando, ao mesmo tempo, uma infra-estrutura agrícola, seria realmente a melhor alternativa que teriam, no momento, para alcançar um melhor nível desenvolvimentista no nordeste. Veja procurou narrar os projetos de colonização, as pequenas vilas que nasceram ao longo da estrada, chegando a serem comparadas pela revista com "cidades do futuro". Por fim, após a inauguração da primeira etapa da rodovia, em agosto de 1972, toda a pompa e exaltação em torno da estrada cessam, e desaparece das páginas da revista, restando apenas algumas frases isoladas em outras matérias de contextos mais amplos, em que Veja cita o fracasso da construção da Transamazônica.

Em relação às construtoras da Transamazônica, Veja tratou das empresas que poderiam vir a participar do edital de concorrência para a construção, deixando claro desde este momento, quais seriam para a revista as mais capazes e estáveis para tal empreitada. Como exemplo, percebemos a Construtora Mendes Júnior, que mereceu inúmeros elogios nas páginas da revista.

\footnotetext{
${ }^{33}$ Análises obtidas através da Dissertação de Mestrado em História, pelo programa de pós-graduação em História da UNIOESTE. Ver: Rautenberg (2011).
} 
Já a ponte Rio-Niterói foi vista com desconfiança por Veja desde os primeiros trabalhos. Além disso, as discussões giram principalmente em torno das empreiteiras responsáveis pelas obras, do rompimento do contrato, dos atrasos no cumprimento dos prazos, da tentativa de formação de uma CPI, etc. Veja marcou posição na exigência de maiores informações por parte do governo, que procurava manter sigilo em torno das questões que envolvia a obra. Parece clara a postura da revista em relação à construção da ponte. A crítica em torno da inviabilidade, as indagações em torno dos benefícios e conseqüências, ficam ainda mais agravados com as críticas em torno das questões de segurança. Além de reclamar os atrasos dos prazos para entrega da ponte, Veja se utiliza das falas de técnicos para afirmar que esta não estaria sendo planejada corretamente. Para agravar o peso da crítica, as inúmeras mortes ocorridas por falta de segurança e o encobrimento sobre estes fatos, são pratos cheios para Veja apoiar sua crítica. Partindo dessas reflexões, chegamos a uma hipótese em relação ao consórcio construtor inicial da ponte, que é o principal alvo dos ataques da revista. Após a mudança do consórcio construtor, passando a obra ao Consórcio Construtor Guanabara (formado pelas empresas Camargo Correa, Rabello S.A. e Mendes Júnior), e o término da ponte, as críticas de Veja permanecem, questionando especialmente sobre a viabilidade da obra e sobre a necessidade de investir tanto dinheiro naquela construção. Porém, como demonstramos, para Veja isto não seria mais culpa das empresas construtoras e sim do governo que não teria avaliado todas as projeções da obra.

Em relação às hidrelétricas e a Itaipu, pudemos perceber como é importante para a revista a construção da Itaipu. Tanto que este evento se sobreporia a qualquer discussão antes iniciada pelo Brasil e Paraguai e em fase de não resolução. Além disso, a revista procurou mostrar o quanto a construção da usina hidrelétrica seria fundamental para os dois países, até pouco tempo vistos como inimigos devido à guerras e disputas econômicas e territoriais, que agora poderiam trabalhar em torno de um projeto comum que levasse a "boa vontade" dos dois países. Além disso, esta importância dada por Veja à construção de Itaipu, não fica apenas em torno das discussões entre os dois países. Terminados os acordos diplomáticos, não haveria mais duvida quanto à conveniência da construção de Itaipu. E Veja procura evidenciar os benefícios econômicos resultantes para os dois países envolvidos na construção da obra. Para o Brasil, Itaipu significaria a garantia da energia elétrica indispensável para atender à demanda em futuro próximo do parque industrial da Região Centro-Sul. Para o Paraguai, em longo prazo representaria a abertura de infinitas possibilidades de 
industrialização. Mas, em curto prazo, permitiria a duplicação da receita cambial do país, com a venda ao Brasil de pelo menos 50 milhões de dólares, anualmente, em quilowatts que não teriam aplicação em seu território.

Depois de firmado o acordo e iniciada as construções, Veja afirma com toda a segurança sobre a irreversibilidade da construção de Itaipu. A usina, chamada por Veja de "mamute hidrelétrico", deveria gerar cerca de 12,6 milhões de quilowatts - ou 70\% do potencial instalado no país. Como percebemos em nossas análises, a obra é apresentada por Veja como extremamente necessária e indispensável para o crescimento do país. Em relação às construtoras da Itaipu, a revista manteve sua postura de apoio, defendendo as construtoras brasileiras, que dividiam a obra com o consórcio construtor paraguaio.

O trabalho permitiu evidenciar de forma mais clara, a forma com que a revista tratou o sistema político em que vivia o país neste período. No discurso de Veja não parece que o país vivia sob uma ditadura militar. Pelo contrário, a revista enquadrou seu discurso de maneira a parecer uma democracia, em que as pessoas levavam sua vida normal, sem repressão ou exploração. Carlos Fico, em "Reinventando o Otimismo" demonstrou que o governo, com a ajuda da imprensa, buscou constantemente reafirmar esta ideologia de país livre e desenvolvido. O país demonstrado por Veja é aquele de modernização econômica, de eficiência, sendo o controle militar justificado pelo avanço que proporcionou o progresso e a melhoria das condições da sociedade como um todo. Como vimos, não foi o que ocorreu. A concentração de capital e renda foi obtida com o auxilio da contenção salarial da classe trabalhadora que teve sua vida deteriorada.

Cabe ainda enfatizar a articulação que envolvia empresários, militares e exintegrantes do IPES, e que ficou evidente em Veja. Algumas construtoras, como a Camargo Correa e a Rabello, tinham vínculos com líderes do IPES, líderes estes que contribuíram para a articulação do golpe de 1964 e depois tiveram importante atuação no governo. A Construtora Camargo Correa esteve envolvida na construção das três obras analisadas. A Rabello, da Ponte Rio-Niterói e da Rodovia Transamazônica. A Construtora Mendes Júnior também teve participação nas três grandes obras. Apesar de não termos comprovado vínculo direto da construtora com a ditadura, percebemos que a mesma se consolidou devido aos projetos ditatoriais, se tornando uma das maiores construtoras já no início dos anos $1980^{34}$. Em relação ao discurso de Veja, é clara a

\footnotetext{
${ }^{34}$ Autores como Alves (1997) e Chaves (1985) trazem dados que confirmam estas afirmações. 
defesa da revista a estas três empresas. Em relação à construção da Transamazônica, ficou clara a defesa que Veja fez à Construtora Mendes Júnior, dando destaque a mesma, desconsiderando as demais construtoras que participaram da construção da rodovia (sendo dividido entre a Camargo Correa, Rabello, EIT, Queiroz Galvão, Mendes Júnior, S.A. Paulista, Paranapanema e pelos Batalhões de Engenharia do Exército). No caso da Ponte Rio-Niterói, a defesa é visível no sentido da revista construir seu discurso de maneira a defender e autenticar a transferência do Consórcio Construtor Rio-Niterói (formado pelas empresas Construtora Ferraz Cavalcanti, Companhia Construtora Brasileira de Estradas, Servix de Engenharia, Empresas de Melhoramentos e Construção) para o Consórcio Construtor Guanabara (Camargo Correa, Rabello S/A, Mendes Júnior). As grandes construtoras são a todo tempo defendidas por Veja, que procura demonstrar que o resultado final da ponte só teria sido possível com a transferência do contrato às empresas capacitadas para tal empreendimento. Já a Hidrelétrica de Itaipu, cujo consórcio construtor englobou as empresas Cetenco, Andrade Gutierrez, Camargo Correa, Mendes Júnior e a Companhia Brasileira de Projetos e Obras, recebeu todos os elogios da revista, cuja característica se configurou na defesa do consórcio brasileiro em detrimento do paraguaio, e nos elogios ao andamento da obra.

\section{Considerações finais}

Como podemos perceber, a revista defendeu tanto os empresários, quanto os militares, construindo seu discurso de maneira a elogiar os projetos governamentais e indicar os melhores caminhos para o desenvolvimento econômico. Nosso recorte levou em consideração às empresas de construção civil, mas isto já nos permite evidenciar Veja como lugar de busca e construção de consenso, e também de articulação de interesse.

A revista procurou construir o avanço da industrialização como um marco obtido com a ditadura, procurando apagar o período populista. Percebe-se então que os golpes finais contra o populismo e a desarticulação das classes populares, obtido com o Golpe de Estado de 1964, são várias vezes reafirmados e defendidos por Veja, já que para a revista, este levou ao desenvolvimento do país. 


\section{Referências Bibliográficas}

ALVES, Patrícia Maria Costa. Relacionamento Cliente/Fornecedor na Indústria da Construção Civil: novas tendências voltadas para um contexto de qualidade e produtividade. Dissertação de Pós-Graduação em Engenharia de Produção e Sistemas, UFSC, 1997.

BETTO, Frei. Batismo de sangue: guerrilha e morte de Carlos Marighella. Rio de Janeiro: Rocco, 2006.

CÂMARA BRASILEIRA DA INDÚSTRIA DA CONSTRUÇÃO CIVIL (CBIC). Coordenação: Daniel Ítalo R. Furletti e Maurício Rosco. Elaboração: Luciene Pires Teixeira. A indústria da construção brasileira no início do século XXI. Belo Horizonte, outubro de 1998.

CHAUVENAU. Agnes. Questões para a história do presente. SP: EDUSC, 1999.

CHAVES, Marilena. A indústria da construção no Brasil: desenvolvimento, estrutura e dinâmica. Rio de Janeiro: dezembro de 1985. Tese (Mestrado) - Programa de PósGraduação do Instituto de Economia Industrial da Universidade Federal do Rio de Janeiro - UFRJ.

DIAS, Edmundo. Hegemonia: racionalidade que se faz história. In: DIAS, Edmundo (Org.). O outro Gramsci. São Paulo, 1996.

DREIFUSS, Armand René. 1964: A conquista do Estado - Ação política, poder e golpe de classe. Rio de Janeiro, $6^{\text {a }}$ edição, Vozes, 2006.

FERNANDEZ, Erico. (Org.). Contrapontos. Ensaios de História Imediata. Porto Alegre, Folha da História, 1999.

FICO, Carlos. Reinventando o otimismo. Rio de Janeiro: Fundação Getúlio Vargas, 1997.

FICO, Carlos. Além do Golpe - Versões e controvérsias sobre 1964 e a Ditadura Militar. Editora Record - 2004.

FONTANA, Josep. História: análise do passado e projeto social. Bauru, SP: EDUSC, 1998. 
FONTES, Virginia Maria; MENDONÇA, Sonia Regina de. História do Brasil Recente. 1964/1992. SP: Ática, 1996.

GOLIN, Tau. Araguaia, o espectro que ainda ronda a esquerda brasileira. In: Revista de Fil. E Ciências Humanas. Passo Fundo, Ano 12, 1996.

GORENDER, Jacob. Combate nas trevas. A esquerda brasileira: das ilusões perdidas à

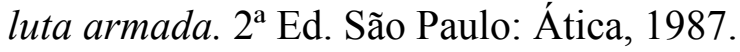

GRAMSCI, Antonio. "Introdução ao estudo da filosofia e do materialismo histórico". IN: Concepção Dialética da História. 9a edição. Rio de Janeiro, Civilização Brasileira, 1991.

JOSÉ, Emiliano. Carlos Marighella: o inimigo número um da ditadura. São Paulo: Casa Amarela, 2004.

LE MONDE DIPLOMATIQUE. Pensamiento crítico versus pensamiento único. Madrid: Debate, 1998.

MARQUES, Eduardo Cesar. Redes Sociais e permeabilidade do Estado: instituições e atores políticos na produção da infra-estrutura urbana no Rio de Janeiro. Tese de doutorado em Ciência Política - Universidade Estadual de Campinas, 1998.

MIR, Luís. A revolução impossivel: a esquerda e a luta armada no Brasil. São Paulo: Best Seller, 1994.

MORAIS, Taís. SILVA, Eumano. Operação Araguaia: os arquivos secretos da guerrilha. São Paulo: Geração Editorial, 2005.

RAUTENBERG, Edina. A revista Veja e as empresas da construção civil. Dissertação de Mestrado em História - UNIOESTE, Marechal Cândido Rondon - PR, 2011.

A revista Veja e os grupos guerrilheiros no Brasil (1968/1972). In: Revista História e Luta de Classes. Dossiê Militares e Luta de Classes. Ano 06. Ed.10, 2010.

A revista Veja e as multinacionais no Brasil (1968-1975). Trabalho de Conclusão de Curso em História - UNIOESTE, Marechal Cândido Rondon - PR, 2008. 
RAUTENBERG, Edina. Veja e a morte de Marighella: moldando discursos em busca de hegemonia. In: ANAIS do I Simpósio de Pesquisa Estado e Poder. UNIOESTE, Marechal Cândido Rondon - PR, 2007.

REIS FILHO, Daniel Aarão. A revolução faltou ao encontro: os comunistas no Brasil. São Paulo; Brasília; Brasiliense; CNPq, 1990.

RIDENTI, Marcelo. O fantasma da revolução brasileira. São Paulo: Editora da Universidade Estadual Paulista, 1993.

SERRA, José. Ciclos e Mudanças Estruturais na Economia Brasileira do Pós-Guerra. In: BELLUZZO, Luiz Gonzaga de Mello; COUTINHO, Renata (Org.).

Desenvolvimento Capitalista no Brasil. Ensaios sobre a crise. São Paulo: Editora Brasiliense, 1982.

SILVA, Carla. Estudando a imprensa para produzir história. III Simpósio Estadual Lutas Sociais na América Latina, 2006, Londrina. In: ANAIS, Crise das democracias latino-americanas: dilemas e contradições. Londrina: eduel, 2006.

TEIXEIRA, Luciene Pires. A indústria de construção brasileira sob a ótica da demanda efetiva. Tese de doutorado pela Universidade Federal de Viçosa (UFV), Minas Gerais, 2009.

VIANA, Nildo. Acumulação Capitalista e Golpe de 1964. In: Revista História \& Luta de Classes. $\mathrm{N}^{\circ} 1$ - Abril - 2005. 